\title{
The relation between alcohol and cardiovascular disease in Eastern Europe: explaining the paradox
}

\author{
Annie Britton, Martin McKee
}

\begin{abstract}
Background-Recent evidence from Eastern Europe of a positive association between alcohol and cardiovascular disease has challenged the prevailing view that drinking is cardioprotective. Consuming amounts of alcohol comparable to those consumed in France has been linked to detrimental cardiovascular effects. One possibility is that this could be related to the particular consequences of binge drinking, which is common in Russia.

Methods-A systematic review of literature on the relation between cardiovascular disease and heavy drinking and irregular (binge) drinking.

Results-Most existing reviews of the relation between alcohol and cardiovascular disease have examined the amount drunk per week or month and have not looked at the pattern of drinking. These have consistently shown that alcohol has a cardioprotective effect, even at high levels of consumption. In contrast, studies that have looked at pattern of drinking, either directly, or indirectly, using indicators such as frequency of hangovers or reports of the consequences of drunkenness, have consistently found an invcreased risk of cardiovascular death, particularly sudden death. A separate review of the physiological basis for a difference between regular heavy drinking and heavy binge drinking demonstrates that the two types of drinking have quite different effects. Conclusion-An association between binge drinking and cardiovascular death meets the standard criteria for causality. It is important that future studies of alcohol related harm examine the pattern of drinking as well as the amount drunk. (F Epidemiol Community Health 2000;54:328-332)
\end{abstract}

Events in the Soviet Union in the $1980 \mathrm{~s}^{1}$ have questioned the conventional wisdom in the West about the cardioprotective effect of alcohol consumption. ${ }^{2}$ This view is exemplified by the statement in the recent WHO/World Bank report on the global burden of disease that "alcohol is cardio-protective at all levels of consumption". In 1985, Russian life expectancy at birth increased by two years within a single calendar year attributable, largely, to a fall in cardiovascular deaths, coinciding with the anti-alcohol campaign instituted by Secretary General Gorbachev. At this time, ${ }^{4}$ and subsequently, ${ }^{5}{ }^{6}$ there has been a close temporal and geographical association between trends in deaths from cardiovascular disease and from causes traditionally associated with alcohol consumption. Further questions emerge from Russia ${ }^{7}$ and in Poland ${ }^{8}$ that have found high rates of cardiovascular death in young men without many traditional risk factors but who were heavy drinkers. However, any suggestion that alcohol could be playing a part seems perplexing, given that France has the lowest death rate from cardiovascular disease in Europe despite official figures suggesting that the amount of alcohol drunk is similar to that in Russia. ${ }^{9}$

In this paper, we argue that this apparent paradox can be explained by the effects of different patterns of drinking. There are important cultural differences between countries that influence how alcohol is consumed. In Mediterranean countries, alcohol is typically consumed as wine with meals, whereas in Russia it is much more likely to be drunk as spirits, in binges. ${ }^{10} \mathrm{~A}$ clue that this might be important is the observation that, in Moscow, there is a significant increase in sudden cardiac death (death within one hour of onset of symptoms) at weekends, most marked among young and early middle aged men, ${ }^{11}$ which is markedly similar to the pattern of deaths from alcohol poisoning and from accidents and violence.

\section{Methods}

A systematic review of relevant published literature was undertaken, based on a search of MEDLINE (years 1966-97) and EMBASE (years 1980-97), follow up of cited references, and information provided by researchers active in alcohol and cardiovascular research. The detailed search strategy is described in a separate report, in which full details of the studies included are given. ${ }^{12}$ The key words used included alcohol, drinking, beer, wine, spirits, mortality, death, coronary heart disease. $\mathrm{MeSH}$ terms included "alcoholism", and "death,-sudden,- cardiac",

Although binge drinking lacks a clear definition in the epidemiological literature, elsewhere it is defined as "indulging in uncontrolled eating or drinking" ${ }^{13}$ It involves episodic drinking to a level usually sufficient to cause inebriation, although quantification is difficult because inebriation reflects factors such as acquired tolerance and, inevitably, such drinking takes place in circumstances where measurement is imprecise and recall problematic. For the present purposes, a loose definition is necessary, encompassing episodic drinking of large amounts of alcohol, often manifest by effects such as drunkenness, hangovers, difficulties with work, and involvement of the police or other authorities. A better definition is, however, required. 
Results

REVIEWS

The relation between alcohol and cardiovascular disease has been examined by several reviewers, taking both narrative and systematic formats. Although some of these narrative reviews have discussed the potential impact of pattern, ${ }^{14}{ }^{15}$ all have categorised exposure in terms of average weekly consumption (sometimes given as a daily equivalent). These studies have focused, almost entirely, on the debate about a cardioprotective effect of moderate drinking. ${ }^{16-28}$ This theme has also been investigated in the systematic reviews, ${ }^{29-31}$ although, again, the potential importance of pattern is identified, although not investigated. ${ }^{32}$

The studies that have examined the association between alcohol and cardiovascular disease have consistently reported a protective effect of moderate alcohol consumption, extending up to at least $80 \mathrm{~g} /$ day. There are, however, two exceptions, both of which are particularly relevant to the question under consideration. The only study that has looked specifically at Russia ${ }^{33}$ failed to find a significant protective effect, after adjustment for the risk profile of the abstainers. The second study that failed to find a protective effect was of the sub-set of subjects in the Nurses' Health Study $^{34}$ who were in the lowest quartile in terms of folate intake. This finding is especially interesting given that the traditional Russian diet is likely to be low in folate.

To explore the issue of binge drinking further, it is necessary to examine in detail those few studies that have examined pattern of drinking or, in the absence of direct measures of quantity and frequency, those that use proxy measures, such as drunkenness, hangovers or a history of problem drinking.

COHORT STUDIES (SEE TABLE 1)

Kauhanen et $a l^{35}$ found that middle aged Finnish men having at least one hangover a month had 2.4 times the risk of cardiovascular death, after adjusting for age and total alcohol intake, than those experiencing fewer hangovers.

Kozarevic et $a l^{\beta 6}$ determined the drinking habits of more than 10000 Bosnian and Croatian men using an alcohol history questionnaire. While drinking was associated with a reduced risk of myocardial infarction and nonsudden cardiovascular death, there was no pro- tective effect for sudden cardiovascular death with a suggestion that the risk increases in the highest consumption category. Of men dying from cardiovascular disease, the more recently a man had been drunk the more likely it was that the death would be sudden. This relation remained after adjustment for factors such as age, blood pressure, smoking, and cholesterol.

Rosengren et $a l l^{37}$ in a 12 year follow up of over 9000 men aged 47 to 55 in Göteborg, Sweden found that "heavy abusers", defined as those registered with the Swedish Temperance Board or who had over four convictions for drunkenness or had received institutional care for alcoholism, experienced an almost doubled risk of death from cardiovascular disease, most of which was attributable to sudden coronary death.

Rossnow and Amundsen ${ }^{38}$ followed up more than 40000 Norwegian conscripts for 40 years. Alcohol abusers had 2.5 times the risk of cardiovascular death than non-abusers. Before the age of 40 , the relative risk was 1.3 , between the ages of 40 and 49 it was 2.6 , and between ages 50 to 59 it increased to 2.8 .

Dyer et $a l,{ }^{39}$ in the People's Gas Company study in Chicago, defined "problem drinkers" as men unable to perform their jobs properly because of chronic problems with alcohol, men with a history of coming to work intoxicated and men suspended from work at some time for alcohol abuse. After 15 years of follow up, alcohol abusers had a 5.2 times increased risk for coronary heart disease mortality, after adjustment for age. The comparable figure for sudden death was 6.5 . The significant relation still existed after further adjustments.

Poikolainen $^{40}$ used information provided in 1953 by 2073 Finnish men on drinking habits including frequency, intoxication, hangovers, hangover drinking (morning drinks) and blackouts. After a 12 year follow up, compared with never being intoxicated during the year, those intoxicated once a week (in the upper social group only) had a 2.5 times increased risk of cardiovascular death. Those with weekly hangovers compared with those never experiencing hangovers had twice the risk of cardiovascular death.

\section{CASE-CONTROL STUDIES}

These findings are supported by several case-control studies. Lithell et $a l^{41}$ found that

Table 1 Cohort studies

\begin{tabular}{|c|c|c|c|c|c|}
\hline Authors & Setting & Inclusion & Sample size & $\begin{array}{l}\text { Length of } \\
\text { follow up } \\
\text { (y) }\end{array}$ & Adjustments \\
\hline Kauhanen J, et al 1997 & $\begin{array}{l}\text { Kuopio town and } \\
\text { rural communities, } \\
\text { Finland }\end{array}$ & $\begin{array}{l}\text { Non-abstinent men aged } \\
42-60 \text { years }\end{array}$ & 2160 & 6.7 (mean) & Age and total alcohol consumption \\
\hline Kozarevic D, et al 1982 & Bosnia and Croatia & Men aged $35-62$ & 11034 & 7 & $\begin{array}{l}\text { Smoking, blood pressure, age, education, serum } \\
\text { cholesterol, liver size, quetelet index }\end{array}$ \\
\hline Rosengren A, et al 1987 & Göteborg, Sweden & Men aged $47-55$ & 9690 & $\begin{array}{l}11.8 \\
\text { (mean) }\end{array}$ & $\begin{array}{l}\text { Previously shown that ". . . association [is] } \\
\text { independent of age, smoking, systolic blood } \\
\text { pressure and serum cholesterol" }\end{array}$ \\
\hline $\begin{array}{l}\text { Rossnow I and Amundsen A } \\
1997\end{array}$ & Norway & $\begin{array}{l}\text { Male conscripts aged } 18-19 \\
\text { years }\end{array}$ & 41399 & 40 & No adjustment for confounding \\
\hline Dyer AR, et al 1977 & Chicago & $\begin{array}{l}\text { White male industrial workers } \\
\text { aged } 40-55 \text { years with no } \\
\text { CHD }\end{array}$ & 1233 & 15 & $\begin{array}{l}\text { Age, diastolic blood pressure, serum cholesterol, } \\
\text { smoking, weight, heart rate }\end{array}$ \\
\hline Poikolainen K, et al 1983 & Finland & $\begin{array}{l}\text { Random stratified sample of } \\
\text { males who purchase alcohol }\end{array}$ & 2076 & 12 & Age and marital status \\
\hline
\end{tabular}


men registered with the Swedish Temperance Board were more than twice as likely to experience sudden cardiac death. Sexton $e t a l^{42}$ found that $14 \%$ of Tasmanian men experiencing sudden cardiac death drank more than 56 drinks per week compared with only $1 \%$ of matched controls selected from the electoral roll. McElduff and Dobson ${ }^{43}$ found that, after adjusting for age, smoking, high blood pressure, cholesterol and several other risk factors, men who drank nine or more drinks a day on one or two days a week had 2.6 times the risk of a major coronary event compared with nondrinkers and who had never been moderate to heavy drinkers. Additional case-control studies are given in the full report. ${ }^{12}$

Importantly, there is a clear physiological basis for the apparent difference between the cardiovascular effects of regular drinking and episodic binge drinking. These have been reviewed in detail elsewhere ${ }^{44}$ but, in brief, the two types of drinking have different effects on lipids, clotting, and cardiac muscle. Binge drinking, in animal models, is associated with both a failure to produce the cardioprotective changes in high density lipoprotein that are seen with regular moderate consumption as well as with an increase of atherogenic low density lipoproteins, which is not seen with regular moderate drinking. Episodic binge drinking is associated with an increased risk of thrombosis, occurring after cessation of drinking, in contrast with the reduced risk of thrombosis associated with regular moderate drinking. Episodic binge drinking predisposes to histological changes in the myocardium and conducting system that increase the risk of arrhythmias. Finally, binge drinking reduces the threshold for ventricular fibrillation.

\section{Discussion}

The starting point of this paper was an attempt to reconcile the apparent contradiction between research, largely undertaken in Western countries characterised by a largely moderate and regular pattern of alcohol consumption, which has been interpreted as showing that "alcohol is cardio-protective at all levels of consumption" 3 and evidence from Eastern Europe, where drinking in binges is much more common, which suggests that alcohol has been an important factor in the high rates of cardiovascular death experienced in these countries.

We have concluded that there is considerable evidence to identify the pattern of drinking as the explanation, with a growing volume of research, from both cohort and case-control studies, that "problem-drinkers", whom it is plausible to assume contain many binge drinkers, are at greater risk of cardiovascular death. It is noteworthy that many of these studies are from Scandinavia, where the pattern of drinking resembles that in Russia. Finally, there is also evidence that alcohol is specifically associated with arrhythmias and sudden cardiac death. We suggest that this holds true for both men and women but our findings are hampered by the lack of data on women. Possible interactions with social class, age and environ- ment were indicated in some of the papers and clearly more research is needed to explore these interactions.

Taken alone, these findings can only show association and not a causal link between binge drinking and cardiovascular death. To examine whether such an association is causal requires supplementation with findings from other studies. This can then be tested using the standard criteria set out by Bradford Hill. ${ }^{45}$

Firstly, there is evidence of a temporal relation between binge drinking and death, both in many of the physiological studies and in some of the case-control studies. Furthermore, indirect evidence comes from a study that found that, in Moscow, there is a significant increase in sudden cardiac deaths at weekends, coinciding with a peak in more obviously alcohol related deaths. ${ }^{11}$

Secondly, there is evidence of a doseresponse relation. This was reported, for sudden cardiac death, in four of the studies included in the review by Anderson et $a l^{29}$ and for fatal myocardial infarction in the study of binge drinking by Kauhanen et al. ${ }^{35}$

Thirdly, the physiological evidence reviewed indicates that a causal relation is biologically plausible and, specifically, that the effects of binge drinking are quite different from those seen with regular moderate, and even heavy drinking. ${ }^{44}$

Fourthly, there is evidence that, in societies where binge drinking is common, removal of alcohol is associated with a fall in cardiovascular death rates. This was most obvious in Russia during the 1985 anti-alcohol campaign, the observation that was the stimulus for this review. ${ }^{4}$ A similar effect was, however, also seen in Poland in 1981-82, ${ }^{46}$ with a fall in cardiovascular deaths coinciding with falls in deaths from accidents and cirrhosis, at a time when availability of alcohol was greatly reduced during the imposition of martial law. ${ }^{47}$

Fifthly, the relation is relatively specific, with a much stronger association seen for sudden cardiac deaths than for non-fatal myocardial infarction. ${ }^{48}$ This is also consistent with the physiological evidence.

Sixthly, the relation is strong, with relative risks of sudden death among problem or binge drinkers compared with others of two to six.

Finally, the association between problem drinking, which we consider to be a reasonable proxy for binge drinking, is consistent.

In summary, therefore, the association between binge drinking and sudden cardiovascular death appears to be causal, thus providing a mechanism for the observed association between alcohol consumption and cardiovascular disease in Eastern Europe.

Two other issues, although supported by rather less evidence, must not be overlooked. Firstly, in central and eastern Europe and the former Soviet Union the traditional diet is low in many micronutients. The findings of the Lipid Research Clinics ${ }^{33}$ and the Nurses' Health Study ${ }^{34}$ that the cardioprotective effect of drinking may be absent in Russians and in those with low folate intakes suggests that care is necessary when advising that even moderate 
drinking is beneficial for coronary heart disease in this region, in the absence of further research on the interaction between nutrition and drinking. A better understanding of this relation and of the micronutrient status of the population of central and eastern Europe is a priority for research.

Secondly, it is likely that some deaths associated with alcohol are actually attributable to drinking contaminated products. White has catalogued a series of examples of people drinking mixtures containing methanol, ether, and a diverse variety of other solvents. ${ }^{10}$ However, it is not possible to quantify this contribution or how consumption of adulterated products has changed over time and, given the evidence of this review, it is not necessary to invoke it as a major cause of the Russian mortality crisis. Furthermore, there is a danger that a focus on illicit, contaminated alcohol will detract from the need to promote sensible consumption of legal alcohol products.

The conclusion that the association between binge drinking and cardiac death is likely to be causal has wider implications. For many years Ledermann's theory on the distribution of drinking within a population was widely accepted. In brief, this stated that, within a population, knowledge of the mean level of alcohol consumption was sufficient to describe the distribution of those drinking at different levels. ${ }^{49}$ It has subsequently been argued that this is incorrect ${ }^{50}$ so that those seeking to assess the harm arising from alcohol in a particular society must determine the actual distribution of levels of drinking. The evidence reviewed here emphasises the additional importance of determining the pattern of drinking. A recent study of the epidemiology of cirrhosis, which showed the importance of episodic drinking other than with meals also indicates that the pattern of drinking may be important for other aspects of alcohol related damage to health. ${ }^{51}$

It also has important implications for policy makers in the west, especially those seeking to promote "sensible drinking". It is essential that they present clearly the message that, while regular moderate drinking (defined as 2-3 units for women and 3-4 units for men per day by the UK Government) may be good for your heart, the same total weekly amount drunk irregularly, in binges, may have the opposite effect. This is especially important as those most likely to drink in binges are often clustered on the margins of society. ${ }^{52}$ This message should also take account of the increasing frequency of binge drinking among women in some societies. ${ }^{53}$

It has not been possible, on the basis of the evidence available, to estimate the extent to which the burden of cardiovascular disease in central and eastern Europe and the former Soviet Union is attributable to alcohol. This review has shown that existing models of attribution are likely to be of limited validity and that this topic requires further research. On the basis of the observed relation between mortality from directly alcohol related and cardiovascular disease since the mid-1980s, it is likely to be substantial.
We are grateful to Dr David Leon, Professor Gerry Shaper, Dr Peter Anderson and Dr Adrian Reynolds for valuable comments.

Funding: this research was funded by the UK Department for International Development. However DfID can accept no responsibility for the views expressed.

\section{Addendum}

The finding that there is a significant increase in sudden cardiac deaths at weekends ${ }^{11}$ has subsequently been replicated in Scotland, where the effect was seen only in those dying suddenly, who had no previous hospital admissions for heart disease. ${ }^{54}$

1 Chenet L, McKee M, Fulop N, et al. Changing life expectancy in central Europe: is there a single reason? f Public Health Med 1996; 18:329-36.

2 St Leger AS, Cochrane AL, Moore F. Factors associated with cardiac mortality in developed countries with particuwith cardiac mortality in developed countries with particular referen

3 Murray CJL, Lopez AD, eds. The global burden of disease. Boston MA: WHO, Harvard School of Public Health, Boston MA: WHO, Haryar
World Bank, 1996:307-8.

4 Leon D, Chenet L, Shkolnikov VM, et al. Huge variation in Russian mortality rates 1984-1994: artefact, alcohol, or what? Lancet 1997;350:383-8.

5 McKee M, Sanderson C, Chenet L, et al. Seasonal variation in mortality in Moscow. F Publ Health Med 1998;20:26874.

6 Walberg P, McKee M, Shkolnikov V, et al. Economic change, crime, and mortality crisis in Russia: a regional analysis. $B M \mathcal{F} 1998 ; 317: 312-18$.

7 Shestov DB, Deev AD, Klimov AN, et al. Increased risk of coronary heart disease death in men with low total and low-density lipoprotein cholesterol in the Russian Lipid Research Clinics Prevalence Follow-up Study. Circulation 1993;88:846-53.

8 Broda G, Davis CE, Pajak A, et al. Poland and the United States Collaborative Study on cardiovascular Epidemiology. A comparison of HDL cholesterol and its subfractions in populations covered by the United States Atherosclerosis Risk in Communities Study and the Pol-MONICA

Project. Arterioscler Thromb Vasc Biol 1996;16:339-49.
9 Simpura J. Trends in alcohol consumption and drinking patterns: lessons from world-wide development. In: Holder HD, Edwards G, eds. Alcohol policy and public policy: Evidence and issues. Oxford: Oxford Medical Publications, 1995:9-37.

10 Bobak M, McKee M, Rose R, et al. Alcohol consumption in national sample of the Russian Population. Addiction 1999;94:857-66.

11 Chenet L, McKee M, Leon D, et al. Alcohol and cardiovascular mortality in Moscow, new evidence of a causal association. F Epidemiol Community Health 1998;52:772-4.

12 Britton A, McKee M, Leon DA. Cardiovascular disease and heavy drinking: A systematic review. London: LSHTM, heavy.

13 Concise Oxford English Dictionary. Oxford: Oxford University Press, 1990

14 Lelbach WK. Organic pathology related to volume and pattern of alcohol use. In: Gibbins RJ, Israel Y, Kalant $\mathrm{H}$, et al. Recent advances in alcohol and drug probems. New York: John Wiley, 1974

15 Kannel WB. Alcohol and cardiovascular disease. Proc Nutr Soc 1988;47:99-110

16 Marmot MG. Alcohol and coronary heart disease. Int f Epidemiol 1984;13:160-7.

17 Moushmoush B, Abi-Mansour P. Alcohol and the heart: The long term effects of alcohol on the cardiovascular system. Arch Intern Med 1991;151:36-42.

18 Beaglehole R, Jackson R. Alcohol, cardiovascular diseases and all causes of death: a review of the epidemiological evidence. Drug Alcohol Rev 1992;11:275-90.

19 Klatsky AL. Epidemiology of coronary heart diseaseKlatsky AL. Epidemiology of coronary heart disease-
influence of alcohol. Alcohol Clin Exp Res 1994;18:88-96.

20 Royal Colleges of Physicians, Psychiatrists, and General Practitioners. Alcohol and the heart in perspective: sensible limPractitioners. Alcohol and the heart in perspective:s
its reaffirmed. London: Royal Colleges, 1995.

its reaffirmed. London: Royal Colleges, 1995 .
Doll R. One for the heart. BMF 1997;315:1664-8.

22 Renaud S, Crigui MH, Farchi F, et al. Alcohol drinking and coronary heart disease. In: Vershuren PM, ed. Health issues related to alcohol consumption. Washington DC: ILSI Press, 1993

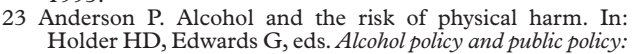
evidence and issues. Oxford: Oxford Medical Publications, 1995:38-61.

24 Shaper AG, Wannamathee G, Walker M. Alcohol and mortality in British men: explaining the U-shaped curve. Lancet 1988;ii: 1267-73.

25 Edwards G, Anderson P, Babor TF, et al. Alcohol policy and the public good. Oxford: Oxford University Press, 1994.

26 Holder HD, Edwards G, eds. Alcohol policy and public policy: evidence and issues. Oxford: Oxford Medical Publications, 1995. 
27 Vershuren PM, ed. Health issues related to alcohol consumption. Washington DC: ILSI Press, 1993.

28 Zakhari S, Wassef M, eds. Alcohol and the cardiovascular system. Research Monograph No 31. Bethesda, MD: National Institute on Alcohol Abuse and Alcoholism, 1996.

29 Anderson P, Cremona A, Paton A, et al. The risk of alcohol. Addiction 1993;88: 1493-508.

30 Holman CDJ, English DR, Milne E, et al. Meta-analysis of alcohol and all-cause mortality: a validation of NHMRC recommendations. Med f Austr 1996;164:141-5.

31 Maclure M. Demonstration of deductive meta-analysis: ethanol intake and risk of myocardial infarction. Epidemio Rev1993;15:328-51.

32 Poikolainen K. Alcohol and mortality: a review. 7 Clin Epidemiol 1995;48:455-65.

33 Deev A, Shestov D, Abernathy J, et al. Association of alcohol consumption to mortality in middle-aged US and Russian men and women. Ann Epidemiol 1998;8:147-53.

34 Rimm EB, Willett WC, Hu FB, et al. Folate and vitamin B6 from diet and supplements in relation to risk of coronary from diet and supplements in relation to risk of coronary

35 Kauhanen J, Kaplan GA, Goldberg DD, et al. Frequent hangovers and cardiovascular mortality in middle-aged men. Epidemiology 1997;8:310-14.

36 Kozarevic D, Demirovic J, Gordon T, et al. Drinking habits and coronary heart disease. The Yugoslavia cardiovascular disease study. Am f Epidemiol 1982;116:748-58.

37 Rosengren A, Wilhelmsen L, Pennert K, et al. Alcoholic intemperance, coronary heart disease and mortality in middle-aged Swedish men. Acta Med Scand 1987;222:20113.

38 Rossnow I, Amundsen A. Alcohol abuse and mortality: a 40-year prospective study of Norwegian conscripts. Soc Sci Med 1997;44:261-7.

39 Dyer AR, Stamler J, Paul O, et al. Alcohol consumption, cardiovascular risk factors, and mortality in two Chicago epidemiologic studies. Circulation 1977;56:1067-74.

40 Poikolainen K. Inebriation and mortality. Int 7 Epidemiol 1983;12:151-5.
41 Lithell $\mathrm{H}$, Aberg $\mathrm{H}$, Selinus I, et al. Alcohol intemperance and sudden death. BMF 1987;294:1456-8.

42 Sexton PT, Jamrozik K, Walsh J, et al. Risk factors for sudden unexpected cardiac deaths in Tasmanian men. Austr NZ F Med 1997;27:45-50.

43 McElduff P, Dobson AJ. How much alcohol and how often? Population based case control study of alcohol consumption and risk of major coronary event. BMF 1997;314: 1159-64.

44 McKee M, Britton A. The positive relationship between alcohol and heart disease in eastern Europe: potential physiological mechanisms. f $R$ Soc Med 1998;91:402-7.

45 Hill AB. The environment and disease: Association or causation? Proc R Soc Med 1965;58:295-300.

46 WHO. Health for All database. Copenhagen: WHO, 1998.

47 Garton Ash T. The Polish revolution. London: Granta, 1991.

48 Wannamethee G, Shaper AG. Alcohol and sudden cardia death. Br Heart f 1992;68: 443-8.

49 Ledermann S. Alcool, alcoolisme, alcoolisation. Vol 1. Paris: Presses Universitaires de France, 1956.

50 Skog O-J. The collectivity of drinking culture: A theory of the distribution of alcohol consumption. $B r f$ Addiction $1985 ; 80: 83-99$.

51 Bellentani S, Saccoccio G, Costa G, et al. Drinking habits as cofactors of risk for alcohol induced liver damage. Gut 1997;41:845-50.

52 Lee AJ, Crombie IK, Smith WCS, et al. Alcohol consumption and unemployment among men: the Scottish Heart Health Study. Br F Addiction 1990;85:1165-70.

53 Mercer PW, Khavari K. Are women drinking more like men? An empirical examination of the convergence hypothesis. Alcohol Clin Exp Res 1990;14:461-6.

54 Evans C, Chalmers J, Capewell S, et al. "I don't like Mondays"-day of the week of coronary heart disease deaths in Scotland: study of routinely collected data. $B M Y$ 2000;320:218-19. 